- Monitoring tooth wear by taking study models and giving a set to the patient should overcome problems of patients or dentists moving address.

- Not all dentists took study casts after the consultant appointment.

- The main reasons for referring patients for tooth wear were concerns about progression and appearance of the teeth.

- It is not clear how the tooth wear is monitored if study casts are not taken.

\title{
An audit of study casts used to monitor tooth wear in general practice
}

\author{
D. W. Bartlett, ${ }^{1}$ I. Palmer ${ }^{2}$ and P. Shah ${ }^{3}$
}

\begin{abstract}
Objective To assess the outcome of compliance of advice sent to patients and dentists about monitoring tooth wear in general practice.
\end{abstract}

Method Postal questionnaires were sent to 70 patients and their dentists requesting information on the outcome of letters of advice sent to general dental practitioners regarding monitoring tooth wear with study casts. They also requested information about the reasons for the patients' referral, the outcome of treatment and whether study models had been taken.

Results Replies were received from 60 dentists (87\%) and 53 patients (75\%). Of these, 16 patients and 16 dentists had moved from their recorded address. Study casts were reported as having been taken by 23 dentists (38\%) and reported by 18 patients (34\%). The most common reason for referral was advice about monitoring the wear and the appearance of their teeth.

Conclusions The compliance of the patients and dentists in monitoring tooth wear by using study casts in general practice was not successful. It raises issues regarding the value of consultant advice letters to this common clinical problem.

\section{INTRODUCTION}

The management of tooth wear remains both an expensive and potentially destructive process. In 2003 a paper reported that tooth wear was either static or slowly progressive in 34 individuals referred to Guy's Dental Hospital for the management of tooth wear. ${ }^{1}$ In that paper patients who had been referred for management of their tooth wear were given standard information and advice on dietary causes of tooth wear and study models were taken to monitor the tooth wear. The outcome of the

\footnotetext{
1"Senior Lecturer/Honorary Consultant in Restorative Dentistry, GKT Dental Institute, King's College, London;

${ }^{2}$ Senior House Officer, GKT Dental Institute, King's College, London; ${ }^{3}$ MClin Dent Student, Eastman Dental Institute, 256 Gray's Inn Road, London

*Correspondence to: Dr David Bartlett, Department of Prosthodontics, Floor 25 Guy's Tower, St Thomas' Street, London SE1 9RT

Email:david.bartlett@kcl.ac.uk
}

\section{Refereed Paper}

Received 23.11.04; Accepted 12.04.05

doi: $10.1038 /$ sj.bdj.4812570

๑ British Dental Journal 2005; 199: 143-145 paper by Bartlett reported that only 7\% of surfaces showed progression and the implication was that, in these patients, monitoring tooth wear was a safe and pragmatic method to conserve teeth. However, by implication, the success of monitoring relies on someone taking and dating the study casts and then using them to compare the rate of progression. If the study casts are not taken then this process fails.

One reason for undertaking the initial study was to investigate how rapid tooth wear was in these patients as there are few data to assist clinicians in this analysis. There are a number of techniques available to accurately measure tooth wear but they remain research methods and as yet are not suitable for routine clinical use. ${ }^{2-5}$ Therefore, study casts remain the most convenient method to assess progression.

Using study casts to monitor tooth wear is a routine followed by many clinicians. Storing all the study casts of patients referred to dental hospitals is not feasible. Therefore, many consultant clinicians advise their referring practitioners to take the study casts and to monitor tooth wear in general practice using study casts. Some suggest that the practitioners should take the study casts and give a copy to the patient, just in case either the dentist or the patient moves address. Without the study casts, the concept of monitoring becomes invalid.

The aim of this study was to assess if study casts were taken by dentists of patients presenting with tooth wear in general practice.

\section{METHOD AND MATERIALS}

The audit process was undertaken at Guy's Dental Hospital in London. The first author receives referrals from general practitioners over a wide area in the South East of England. Patients seen on the consultant clinic are examined and a letter sent to the referring practitioner with information on the management of the patient. The authors reviewed all the letters sent during that period and selected only those that advised the referring practitioner to monitor tooth 
wear with study casts. Letters giving advice on the restoration or agreeing to provide treatment were not selected. The audit process covered the period from January 2000 to February 2003, a total of three years.

A questionnaire was composed and sent to both the referring dentist and their patient asking similar information (Tables 1 and 2). The first draft of the questionnaire was piloted on colleagues in practice and a small number of typographical and changes for clarity were made. The final questionnaire was designed to be simple but focused on whether the study casts were taken. The questionnaire was sent out in May 2004 with a stamped addressed envelope. A second set was sent to nonresponders in July 2004 and finally, those not responding to the questionnaire after these two attempts were telephoned and

\section{Table 1 Questionnaire to dentists \\ Please circle the most appropriate answer \\ 1. Study casts were made of the patient's mouth soon after the appointment at Guy's \\ Yes \\ No \\ Can't remember \\ 2. If taken, where are the casts? \\ Given to patient \\ At the practice \\ Can't remember \\ 3. Which bests describes your concerns regarding the referral to the hospital for your patient? \\ I was primarily concerned about the appearance of the worn teeth \\ I was primarily concerned that the tooth wear was prevented from getting worse \\ Combination of both}

4. Which best describes your reasons for referral? I was looking for advice on a treatment plan on how to manage the tooth wear

I was hoping that the treatment could be provided my the dental hospital

\section{Which best describes the visit to the hospital}

I felt that the appointment was very worth while I felt that the appointment was worthwhile I felt that the appointment was not worthwhile

\section{Following the outcome of the} appointment which best describes the subsequent management?

I provided fillings / crowns to improve the appearance / protect the teeth

I will be providing fillings / crowns to improve the appearance / protect the teeth

The patient is undergoing a review process

Please add any further comments that you may feel would be helpful (you may continue overleaf if necessary) the questionnaire either sent again or their answers were recorded over the phone. The final returns were completed in October 2004. The main questions related to whether study casts had been taken and why the referral had been sent to the dental hospital. The final section of the questionnaire allowed both parties to make free text comments.

\section{RESULTS}

A total of 70 questionnaires were sent to patients and 70 questionnaires sent to the referring dentists. The majority of patients lived in London and Kent but the dentists practised over a wider area (Table 3). The patients had a median age of 40.5 years (interquartile range 30-53 years old) and most were male (45 or $64 \%$ male and 25 or $36 \%$ women). The dentists were mostly male (54 or 77\%) with fewer women (16 or $23 \%$ ).

\section{Table 2 Questionnaire to patients}

Please circle the most appropriate answer

\section{Moulds were taken of my mouth soon after} the appointment at Guy's

Yes

No

Can't remember

2. My dentist already had a set of models to compare

Yes

No

Don't know

3. My dentist gave me models of my mouth to keep Yes

No

Can't remember

4. Which best describes the reason for your referral to the hospital?

I was primarily concerned about the appearance of my teeth

I was primarily concerned that the tooth wear was prevented from getting any worse Combination of both

5. Which best describes your visit to the hospital I felt that the appointment was very worthwhile I felt that the appointment was worthwhile I felt that the appointment was not worthwhile

6. Following the outcome of the appointment which best describes your subsequent care? I received fillings/crowns/caps to improve the appearance / protect my teeth

I am waiting for fillings / crowns / caps to improve the appearance / protect my teeth I am undergoing a review / monitoring process Please add any further comments that you may feel would be helpful (you may continue overleaf if necessary)
Table 3 Distribution of referring dentists and patients

\begin{tabular}{lcc}
\hline & Patients & Dentists \\
London & 25 & 22 \\
Kent & 17 & 14 \\
E and W Sussex & 8 & 9 \\
Essex & 8 & 8 \\
Norfolk & 3 & 3 \\
Buck & 5 & 2 \\
Surrey & 3 & 3 \\
Worcestershire & & 1 \\
York & & 1 \\
Herts & & 1 \\
Berkshire & & 2 \\
Coventry & & 1 \\
Hampshire & & 1 \\
Dorset & & 1 \\
Cheshire & & 1 \\
Totals & 70 &
\end{tabular}

There were 53 replies from patients $(75 \%)$ and $60(87 \%)$ from dentists and of these $16(30 \%)$ patients and 16 (26\%) dentists had moved from their recorded address (Table 4). Patients and dentists did not answer every question. Twenty-three dentists (38\%) reported taking study casts but $18(30 \%)$ did not and the most common reason for this was that the patient failed to return. Eighteen patients (34\%) reported not having had the study casts taken while $14(26 \%)$ reported having had their impressions. Three dentists (5\%) and five patients (1\%) could not remember either taking the study casts or having had them. Both the dentists and the patients reported that giving the study casts to the patients was rare.

The main reason for referral from both groups was concern over the rate of progression of tooth wear or a combination of dissatisfaction with the appearance of the teeth and concern over progression. Overall, both groups considered the examination a worthwhile procedure. The dentists mainly wanted advice (23 or 38\%) for treatment planning although some (12 or 20\%) wanted the dental hospital to carry out the treatment. The treatment received by the patients was mostly that of reviewing the tooth wear (21 or 39\%) although a considerable number received restorations (17 or $32 \%)$. A total of 27 (39\%) replies could be matched between dentist and patient. In reply to whether the study casts had been taken 18 (66\%) agreed on their answer (11 had casts and eight did not) while there was disagreement between three (11\%) and the remaining six $(22 \%)$ patients could not remember although the dentist reported doing so.

The free text comments from the dentists and the patients varied considerably. 


\begin{tabular}{|c|c|c|c|c|c|c|}
\hline & Dentist & & & Patient & & \\
\hline $\begin{array}{l}\text { Were study } \\
\text { casts taken? }\end{array}$ & $\begin{array}{l}\text { Yes } \\
23\end{array}$ & $\begin{array}{l}\text { No } \\
18\end{array}$ & $\begin{array}{l}\text { Can't } \\
\text { remember } \\
3\end{array}$ & $\begin{array}{l}\text { Yes } \\
14\end{array}$ & $\begin{array}{l}\text { No } \\
18\end{array}$ & $\begin{array}{l}\text { Can't } \\
\text { remember } \\
5\end{array}$ \\
\hline Casts & $\begin{array}{l}\text { Given to } \\
\text { patient } \\
6\end{array}$ & $\begin{array}{l}\text { Kept in } \\
\text { practice } \\
14\end{array}$ & $\begin{array}{l}\text { No record } \\
1\end{array}$ & $\begin{array}{l}\text { Kept by } \\
\text { patient } \\
4\end{array}$ & $\begin{array}{l}\text { Kept in } \\
\text { practice } \\
32\end{array}$ & $\begin{array}{l}\text { Can't } \\
\text { remember } \\
2\end{array}$ \\
\hline $\begin{array}{l}\text { Reasons for } \\
\text { referral }\end{array}$ & $\begin{array}{l}\text { Appearance } \\
2\end{array}$ & $\begin{array}{l}\text { Progression } \\
16\end{array}$ & $\begin{array}{l}\text { Both } \\
18\end{array}$ & $\begin{array}{l}\text { Appearance } \\
2\end{array}$ & $\begin{array}{l}\text { Progression } \\
22\end{array}$ & $\begin{array}{l}\text { Both } \\
12\end{array}$ \\
\hline Outcome of visit & $\begin{array}{l}\text { Worthwhile } \\
26\end{array}$ & $\begin{array}{l}\text { Not } \\
\text { worthwhile } \\
10\end{array}$ & $\mathrm{~N} / \mathrm{A}$ & $\begin{array}{l}\text { Worthwhile } \\
27\end{array}$ & $\begin{array}{l}\text { Not } \\
\text { worthwhile } \\
8\end{array}$ & $\mathrm{~N} / \mathrm{A}$ \\
\hline Outcome & $\begin{array}{l}\text { Review } \\
21\end{array}$ & $\begin{array}{l}\text { Restorations } \\
17\end{array}$ & $N / A$ & $\begin{array}{l}\text { Review } \\
21\end{array}$ & $\begin{array}{l}\text { Restorations } \\
4\end{array}$ & $\begin{array}{l}\text { Waiting for } \\
\text { restorations } \\
7\end{array}$ \\
\hline $\begin{array}{l}\text { Reasons for } \\
\text { referral }\end{array}$ & $\begin{array}{l}\text { Referral to } \\
\text { hospital } \\
12\end{array}$ & $\begin{array}{l}\text { Advice } \\
23\end{array}$ & N/A & N/A & $\mathrm{N} / \mathrm{A}$ & N/A \\
\hline
\end{tabular}

Some patients complained about the length of time it took for the hospital appointment allied to their expectation that the hospital would carry out the treatment and these patients assessed their experience as not worthwhile. Other comments included "what was happening to my tooth wear was explained and the experience very helpful'. The dentists reported that many patients simply did not return to the practice or that restorations were placed and were now under review.

\section{DISCUSSION}

The audit aimed to investigate whether asking dentists to take study casts to monitor tooth wear was a realistic aim. The outcome suggests that only 23 dentists out of 60 approached (38\%) took study casts to monitor the wear. In addition, the standard advice from the dental hospital is for the dentist to give the study casts to the patient and the results indicated that only six dentists and four patients were aware of this happening. In theory, giving the study casts to the patient should overcome the difficulty of patients or dentists moving. As a considerable number of dentists and patients moved during the three year period this advice would seem sensible and it is a pity this appears not to have been carried out. Another reason for giving the patient the study casts is to save space in the dental practice, but this seems not to be an issue with the dentists.

The questionnaire was simple to complete and most dentists assisted with this successfully, whereas it was more difficult to contact the patients. The final few were contacted by phone and the questions were read out and the answers recorded. This proved to be successful for those dentists and patients remaining at the recorded address. The reply rates are within acceptable limits and compare well to other studies, and the use of stamped addressed envelopes helped with the success rate. ${ }^{6,7}$ An original objective was to directly compare the reporting of the patients to their dentists. Unfortunately, because of a large number of patients or dentists leaving their original address this was only possible in around 40\% of cases. Despite this, most reported the same experience, although some patients could not remember having models taken although the dentist reported doing so.

These results raise important questions as to how to manage referrals for tooth wear. It is beyond the financial and manpower resources of dental schools to treat every patient referred for advice and treatment. It is also interesting to note that most patients and dentists considered progression to be the important reason for referring to the hospital. The study reported by Bartlett on progression suggests that tooth wear can be slow and therefore it seems reasonable to monitor rather than treat all wear cases. ${ }^{1}$ However, the results presents a conundrum: is it the responsibility of the dental hospital or the general practitioner to monitor the wear? From a hospital perspective it should be the referring dentist who has the duty of care. Fortunately most dentists fulfilled this duty well. The system breaks down when the patients or the dentists move. More widespread education will raise the numbers of dentists giving study casts to the patients and allow the monitoring process to become more successful.

Most dentists wanted advice on the treatment but a significant proportion wanted the treatment undertaken in the hospital. Often practitioners refer patients not only for the advice but also for protection against litigation and claims about supervised neglect. If a patient agrees to monitoring at the time of the consultant appointment and together with the consultant letter as support it is unlikely that litigation would be successful. It is also not possible for dental hospitals to provide the treatment for all the patients referred.

A surprising finding from the study was that the advice given to the dentist was to continue monitoring and yet 17 patients received restorations. However, it was not possible within the confines of the study to determine what restorations were placed. While the time period of the study covered three years and some restorations might have been expected, it is possible that the reasons for treatment changed over the study time.

\section{CONCLUSION}

The response from patients and practitioners to the questionnaire was good. It showed that only $38 \%$ of dentists replying to the questionnaire took study casts to monitor tooth wear. This leaves the remaining 62\% not using them. While some dentists restored the worn teeth, a significant proportion of patients did not receive the monitoring. This raises questions on how to manage patients with tooth wear in general practice.

The authors are grateful to the dentists and patients who contributed to this paper.

1. Bartlett D W. Retrospective long term monitoring of tooth wear using study models. Br Dent J 2003; 194 211-213.

2. Chadwick R G, Mitchell H L, Cameron I, Hunter B, Tulley M. Development of a novel system for assessing tooth and restorations wear. J Dent 1997 25: 41-47.

3. Azzopardi A, Barlett D W, Watson T F, Sherriff M. The measurement and prevention of erosion and abrasion. J Dent 2001; 29: 395-400.

4. Azzopardi A, Bartlett D W, Watson TF etal. The surface effects of erosion and abrasion on dentine with and without a protective layer. Br Dent J 2004; 196: 351-354.

5. Bartlett D W, Blunt L, Smith B G N. Measurement of tooth wear in patients with palatal erosion. Br Dent 1997; 182: 179-184.

6. Bartlett D W, Coward PY, Goodsman D et al. Experience of undergraduates from three London dental schools and trainers from the south east of England on interviews for vocational training in 1996. Br Dent J 1997; 183: 284-288.

7. Fenlon M R, McCartan B E, Sherriff M etal. Personality of dental students in two dental schools in the United Kingdom and in Ireland. Eur J Dent Educ 2001; 5: 173-176 